\title{
EVALUATION OF DIAGNOSTIC THRESHOLDS DEPENDABILITY FOR TRIBOLOGIC SIGNALS RECEIVED IN THE ENVIRONMENT DISTURBED BY VIBROACOUSTIC AND FUNCTIONAL SIGNALS

\author{
OCENA WIARYGODNOŚCI PROGÓW \\ DIAGNOSTYCZNYCH Z SYGNALÓW \\ TRIBOLOGICZNYCH W OTOCZENIU SYGNALÓW \\ WIBROAKUSTYCZNYCH I FUNKCJONALNYCH
}

\author{
Pawel Lindstedt, Marek Zboiński, Maciej Deliś, Jerzy Manerowski \\ e-mail:marek.zboinski@itwl.pl; maciej.delis@itwl.pl; jerzy.manerowski@itwl.pl
}

\begin{abstract}
Determination of dependable diagnostic thresholds for tribologic signals received e.g. from antifriction bearings (in particular for insufficient number of measurements, only $4 \div 5$ ) is a really difficult task due to complexity of working environment where such bearings are operated. Typical working environment for such objects must take account for operation time under various working conditions and accompanying (and disturbing) signals, e.g. vibroacoustic ones. The sought assessment of the relationship between diagnostic signals and environmental noise can be determined from convolution of both diagnostic and environments signals that make up the complete set of received information. The convolution of these two series of signals can be obtained from an algorithm based on the Cauchy product. Then one has to find the coherence factor and the square of amplitude gain for the set of diagnostic signals with reference to various sets of signals received from environment, which makes it possible to evaluate cohesion of the investigated series of signals, thus their suitability to determine diagnostic threshold for tribologic signals intended for the analysis.
\end{abstract}

Keywords: diagnostic thresholds, tribologic signals

Streszczenie: Wyznaczenie wiarygodnych progów diagnostycznych dla sygnatów tribologicznych $n p$. łożysk tocznych (szczególnie gdy dysponuje sie mała liczba pomiarów 4:5) jest przedsięwzięciem trudnym ze względu ma złożoność otoczenia, w którym tożyska te pracuja. Typowym otoczeniem tego typu obiektów są: czas pracy $w$ różnych warunkach użytkowania $i$ sygnaty towarzyszace $n p$. wibroakustyczne. Poszukiwana ocena relacji miedzy sygnałami diagnostycznymi i otoczeniem może być wyznaczona na podstawie splotu zbioru pomiarów sygnałów diagnostycznych i otoczenia. Splot sygnałów może być zrealizowany wg algorytmu iloczynu Cauchy'ego. Następnie wyznacza się wspótczynnik koherencji i kwadrat wzmocnienia amplitudowego zbioru sygnałów diagnostycznych względem zbiorów różnych sygnałów otoczenia, które pozwalają ocenić spójność badanych zbiorów, a zatem $i$ ich przydatność do wyznaczenia progów diagnostycznych dla analizowanych sygnatów tribologicznych [3, 5, 7, 9].

Stowa kluczowe: progi diagnostyczne, sygnaty tribologiczne 
Evaluation of diagnostic thresholds dependability for tribologic signals...

Ocena wiarygodności progów diagnostycznych z sygnatów tribologicznych...

\section{Wstęp}

W diagnostyce tribologicznej zużyciowej dysponuje się dużymi rozproszonymi zbiorami pomiarów, które realizowane są w różnym czasie i które dotyczą różnych obiektów tego samego typu (np. układów łożyskowania). [4, 14, 15] Przykładowo jednym $\mathrm{z}$ takich zbiorów może być zbiór pomiarów koncentracji żelaza $(\mathrm{Fe})$ próbek oleju wyznaczonych metodą optycznej spektrometrii emisyjnej (MOA) dla układów łożyskowania 2 silników lotniczych (silnik nr 1 i silnik nr 2) - rys 1.

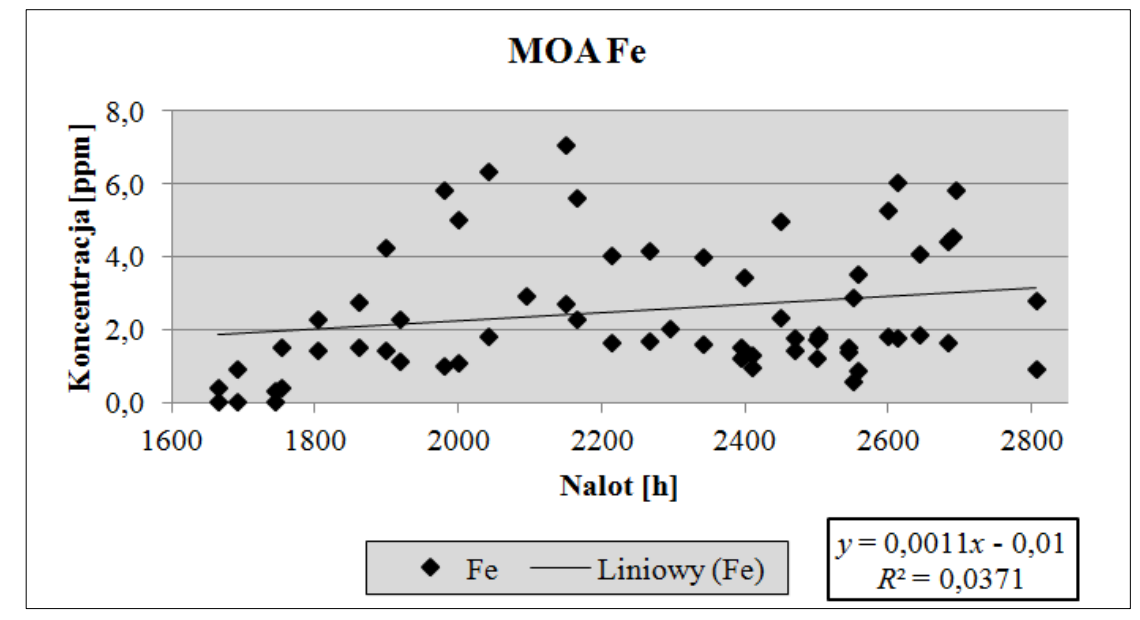

Rys. 1 Koncentracja żelaza w funkcji nalotu, metoda optycznej spektrometrii emisyjnej.

Wyznaczenie progu diagnostycznego przy zastosowaniu tzw. metody 36 wspólnego dla silnika 1 i 2 z wykorzystaniem dużej liczby (37 - w okresie 16002800 godzin 'zmieszanych' pomiarów jest problematyczne (budzi pewne wątpliwości). Dostrzeżono, że:

- próg diagnostyczny zawsze wyznaczany jest na podstawie dużego zbioru pomiarów wielu obiektów. Stworzenie potrzebnego dużego zbioru pomiarów jest czasochłonne (w danym przypadku to 1200 godz.)

- wspólny próg diagnostyczny dla wielu obiektów spowoduje, że dla indywidualnie ocenianych obiektów jest on nieścisły

- jeden wspólny próg diagnostyczny nie uwzględnia wieku obiektu w chwili pomiaru, a także jego otoczenia (np. nalot, trudność nalotu, drgania, temperatura itp.).

Rozwiązania zasygnalizowanych tu problemów jakie spotykamy podczas wyznaczania tribologicznych progów diagnostycznych poszukuje się w następujących przedsięwzięciach:

- tribologiczny próg diagnostyczny należy wyznaczać indywidualne (dla każdego obiektu osobno). Może to nastąpić, gdy dysponuje się już 4-6 pomiarami $\mathrm{z}$ danego obiektu. Takie podejście jest zgodne $\mathrm{z}$ podstawową zasadą diagnostyki, która nakazuje ażeby wszystkie obiekty danego zbioru były traktowane indywidualnie. 
- podczas wyznaczania progu diagnostycznego należy w sposób kompleksowy uwzględnić otoczenie. Mogą to być sygnały funkcjonalne, wibroakustyczne $\mathrm{i}$ inne towarzyszące wynikające $\mathrm{z}$ trudności wykonywanego lotu.

Należy jednak podkreślić, że próg diagnostyczny wyznaczony z 4-6 pomiarów z uwzględnieniem pomiarów otoczenia (np. nalot) będzie wiarygodny wtedy, gdy „spójność" pomiarów sygnałów tribologicznych i otoczenia będzie odpowiednia (koherencja powinna przekroczyć wartość 0,7 )

\section{Baza danych $z$ kompleksowych badań diagnostycznych}

Rezultaty badań funkcjonalnych (nalot) wibroakustycznych (przyspieszenie amplitudy drgań $\frac{A}{s^{2}}$ ) i tribologicznych (koncentracja Fe wyznaczona metodą optycznej spektrometrii emisyjnej MOA) dla 2 silników (silnika nr 1 i silnika nr 2) przedstawiono w tabelach $\mathrm{nr} 1$ i $2 .[9,14,15]$

Tabela 1. Wyniki kompleksowych badań diagnostycznych silnika $\mathrm{nr} 1$.

\begin{tabular}{|c|c|c|c|c|c|c|}
\hline \multirow{2}{*}{$\begin{array}{c}\text { Nr } \\
\text { pomiaru }\end{array}$} & Nalot & Sygn. Trib. & \multicolumn{2}{|c|}{ Sygnal wibroakustyczny } & \multirow{2}{*}{ uwagi } \\
\cline { 4 - 6 } & sygal funk. & MOA Fe & Spręż. & Turb. & Maks. & \\
\hline 1. & 1666 & 0,03 & 9 & 10 & 10 & \\
\hline 2. & 1693 & 0,04 & 10 & 7 & 10 & \\
\hline 3. & 1745 & 0,3 & 12 & 5 & 12 & \\
\hline 4. & 1755 & 1,5 & 9 & 7 & 9 & \\
\hline 5. & 1805 & 2,3 & 8 & 6 & 8 & \\
\hline 6. & 1862 & 2,7 & 7 & 10 & 10 & \\
\hline 7. & 1900 & 4,2 & 10 & 10 & 10 & \\
\hline 8. & 1920 & 1,1 & 10 & 7 & 10 & \\
\hline 9. & 1980 & 1,0 & 13 & 4 & 13 & \\
\hline 10. & 2000 & 5,0 & 10 & 1 & 10 & \\
\hline 11. & 2043 & 6,3 & 13 & 9 & 13 & \\
\hline 12. & 2096 & 9,5 & 11 & 10 & 11 & \\
\hline
\end{tabular}

Tabela 2. Wyniki kompleksowych badań diagnostycznych silnika $\mathrm{nr} 2$.

\begin{tabular}{|c|c|c|c|c|c|c|}
\hline \multirow{2}{*}{$\begin{array}{c}\mathrm{Nr} \\
\text { pomiaru }\end{array}$} & \multirow{2}{*}{$\begin{array}{c}\text { Nalot } \\
\text { sygnal funk. }\end{array}$} & \multirow{2}{*}{$\begin{array}{c}\text { Sygn. Trib. } \\
\text { MOA Fe }\end{array}$} & \multicolumn{3}{|c|}{ Sygnal wibroakustyczny } & \multirow{2}{*}{ uwagi } \\
\hline & & & Spręż. & Turb. & Maks. & \\
\hline 1. & 1666 & 0,4 & 22 & 22 & 22 & \\
\hline 2. & 1693 & 0,9 & 24 & 23 & 14 & \\
\hline 3. & 1745 & 0,0 & 32 & 12 & 32 & \\
\hline 4. & 1755 & 0,4 & 31 & 18 & 31 & \\
\hline 5. & 1805 & 1,4 & 17 & 16 & 17 & \\
\hline 6. & 1862 & 1,5 & 5 & 9 & 9 & \\
\hline 7. & 1900 & 1,4 & 9 & 16 & 16 & \\
\hline 8. & 1920 & 2,3 & 9 & 14 & 14 & \\
\hline 9. & 1980 & 5,8 & 10 & 15 & 15 & \\
\hline 10. & 2000 & 1,1 & 11 & 17 & 17 & \\
\hline 11. & 2043 & 1,8 & 10 & 14 & 14 & \\
\hline 12. & 2096 & 2,9 & 10 & 16 & 16 & \\
\hline
\end{tabular}


Evaluation of diagnostic thresholds dependability for tribologic signals...

Ocena wiarygodności progów diagnostycznych z sygnatów tribologicznych...

Analizując dane z tabel 1 i 2 można zauważyć, że podstawowym zagadnieniem do rozwiązania jest wyznaczenie w krótkim czasie aktualnego progu diagnostycznego kolejno dla silnika 1 i 2, czyli z małej liczby pomiarów (4-6). Z tabel widać bowiem, że 4 pomiary uzyskuje się już po 89 godz. nalotu, a np. 12 pomiarów dopiero po 430 godz. nalotu. Okazuje się, że taka możliwość realnie istnieje pod warunkiem, że posiadane zbiory (4-6) pomiarów są wystarczająco „spójne” (ich koherencja jest odpowiednia - bliska „1”).

\section{Splot - iloczyn Cauchy'ego - koherencja}

Pojęcie splotu dwu funkcji jest szeroko znane i powszechnie stosowane w praktyce. Splot (całka superpozycji, całka Duhamela, ważona średnia bieżąca, wygładzenie, rozmywanie czy też wybieranie) jest specyficzną funkcją o specjalnych właściwościach. Splot funkcji $x(t)$ i $y(t)$ wynosi $[1,3,5,7,9,13]$ :

$$
h_{x y}(t)=\int_{-\infty}^{+\infty} x(t) y(t-\tau) d \tau=\int_{-\infty}^{+\infty} x(t-\tau) y(t) d \tau
$$

Splot funkcji krótko zapisuje się:

$$
\mathrm{h}_{\mathrm{xy}}(\mathrm{t})=\mathrm{x}(\mathrm{t}) * \mathrm{y}(\mathrm{t})=\mathrm{y}(\mathrm{t}) * \mathrm{x}(\mathrm{t})
$$

* - symbol splotu

Można także realizować sploty tych samych funkcji np. $x(t)$ z $x(t)$ i $y(t)$ z $y(t)$. Wtedy otrzymuje się:

$$
\begin{aligned}
& \mathrm{h}_{\mathrm{xx}}(\mathrm{t})=\mathrm{x}(\mathrm{t}) * \mathrm{x}(\mathrm{t}) \\
& \mathrm{h}_{\mathrm{yy}}(\mathrm{t})=\mathrm{y}(\mathrm{t}) * \mathrm{y}(\mathrm{t})
\end{aligned}
$$

Gdy względem splotu $h_{x y}(t)$ lub $h_{x x}(t)$ i $h_{y y}(t)$ zastosuje się przekształcenie Fouriera, to otrzymuje się:

$$
\mathcal{F} \mathrm{h}_{\mathrm{xy}}(\mathrm{t})=[\mathcal{F} \mathrm{y}(\mathrm{t}) * \mathrm{x}(\mathrm{t})]
$$

i dalej jego widmową postać:

$$
H_{x y}(j \omega)=Y(j \omega) \cdot X(j \omega)
$$


Oznacza to, że w zespolonym przekształceniu Fouriera mnożenie transformat $Y(j \omega)$ i $X(j \omega)$ odpowiada splataniu oryginałów $x(t)$ i $y(t)$ (twierdzenie Borela). Ta własność ma szczególne znaczenie w procesie identyfikacji układów (zjawisk). Gdy $y(t)$ jest sygnałem wyjściowym, $x(t)$ sygnałem wejściowym a $h_{x y}(t)$ jest ich splotem wzajemnym oraz $h_{x x}(t)$ splotem własnym sygnału wejściowego, a $h_{y y}(t)$ splotem własnym sygnału wyjściowego to wtedy po zastosowaniu przekształcenia Fouriera względem wszystkich tych funkcji otrzymujemy:

$$
\begin{aligned}
& \frac{H_{x y}(j \omega)}{H_{x x}(j \omega)}=\frac{Y(j \omega) X(j \omega)}{X(j \omega) X(j \omega)}=\frac{Y(j \omega)}{X(j \omega)}=G(j \omega) \\
& \frac{H_{y y}(j \omega)}{X_{x x}(j \omega)}=\frac{Y(j \omega) Y(j \omega)}{X(j \omega) X(j \omega)}=\frac{Y(j \omega)}{X(j \omega)}=A(j \omega)^{2}
\end{aligned}
$$

Gdzie $G(j \omega)$ jest transmitancją widmową identyfikowanego obiektu, zjawiska, układu najogólniej rzecz biorąc dowolnego „bytu”, którego sygnałem wejściowym jest $x(t)$, a sygnałem wyjściowym $y(t)$ (transformaty tych sygnałów $X(j \omega)$ i $Y(j \omega)$ ), a $\mathrm{A}(\mathrm{j} \omega)^{2}$ jest kwadratem wzmocnienia amplitudowego sygnału wyjściowego $y(t)$ względem sygnału wejściowego $x(t)$.

Transmitancja $G(j \omega)$ i wzmocnienie $\mathrm{A}(\mathrm{j} \omega)^{2}$ mogą być wyznaczone bezpośrednio z eksperymentu (mierzy się $x(t)$ i $y(t)$ ) dzięki uprzednio wykonanej operacji splatania sygnałów. Splot dyskretny (iloczyn Cauchy'ego) sygnałów $x(t)$ i $y(t)$ podanych w postaci ciągu liczb $\{x(t)\}$ i $\{y(t)\}$ z numerycznego punktu widzenia jest równoważny dyskretnej postaci transformaty Fouriera [3]. Iloczyn Cauchy'ego dla ciągów liczb $\{x\}$ i $\{y\}$ wynosi:

$$
\begin{gathered}
\left\{x_{0}, x_{1}, \ldots, x_{m}\right\} *\left\{x_{0}, x_{1}, \ldots, x_{m}\right\}=\left\{x_{0} x_{0}, x_{0} x_{1}+x_{1} x_{0}, \ldots, x_{m} x_{n}\right\} \\
\left\{y_{0}, y_{1}, \ldots, y_{m}\right\} *\left\{y_{0}, y_{1}, \ldots, y_{m}\right\}=\left\{y_{0} y_{0}, y_{0} y_{1}+y_{1} y_{0}, \ldots, y_{m} y_{n}\right\} \\
\left\{x_{0}, x_{1}, \ldots, x_{m}\right\} *\left\{y_{0}, y_{1}, \ldots, y_{m}\right\}=\left\{x_{0} y_{0}, x_{0} y_{1}+x_{1} y_{0}, \ldots\right\}
\end{gathered}
$$

gdzie: *- splot sygnałów (iloczyn Cauchy’ego).

Ciąg liczb $\{x\}$ może być otoczeniem (np. nalotem lub sygnałem wibroakustycznym), a ciąg liczb $\{\mathrm{y}\}$ sygnałem diagnostycznym (dowolnym pomiarem tribologicznym). 
Evaluation of diagnostic thresholds dependability for tribologic signals...

Ocena wiarygodności progów diagnostycznych z sygnatów tribologicznych...

Obliczenie splotu ciągu liczb jest proste, co ilustruje rysunek 2.

\begin{tabular}{ccc} 
& 2 & \\
& 1 & \\
2 & 1 & 2 \\
2 & & 4 \\
3 & & 9 \\
3 & & 10 \\
4 & & 13 \\
& & 10 \\
& $\downarrow$ & 8 \\
\hline 14 & 4 & 56
\end{tabular}

Rys. 2 Schemat obliczenia splotu ciagu liczb sygnałów

$z$ badań diagnostycznych (zbiorów $\{2,2,3,3,4\}$ i $\{1,1,2\}$ ).

$\mathrm{Na}$ rysunku 2 przedstawiono splot ciągu liczb $\{2,2,3,3,4\} *\{1,1,2\}$. Ciąg $\{1,1,2\}$ w danym przypadku zapisany jest od dołu do góry i przesuwany jest w dół, aż do pojawienia się kolejnych par ciągu pierwszego i drugiego. Tu, wzorując się na standardowej analizie sygnałów, można ustalić miarę relacji między sygnałami: koherencję i wzmocnienie amplitudowe między sygnałami otoczenia $\{x\}$ i diagnostycznymi $\{y\}$. Sploty własne (iloczyny Cauchy'ego) sygnałów $\{x\}$ i $\{y\}$ i wzajemne (równoważne transformacie Fouriera) mogą być traktowane jako gęstości mocy sygnałów: własne $S_{x x}$ i $S_{y y}$ i wzajemne $S_{x y}$. Interpretacja relacji między sygnałami też jest prosta - zbiór jest skupiony, gdy koherencja $\gamma_{x y}^{2}(\omega) \approx 1$. Zużycie jest prawidłowe, gdy wzmocnienie amplitudowe $|A|^{2}(\omega)<<1$. Koherencję i wzmocnienie amplitudowe oblicza się z zależności [3, 5, 12]:

$$
\begin{gathered}
\gamma_{x y}^{2}(\omega)=\frac{\left|S_{x y}\right|^{2}}{S_{x x} S_{y y}} \leq 1 \\
|A|^{2}(\omega)=\frac{S_{y y}}{S_{x x}}<<1
\end{gathered}
$$

Należy podkreślić, że stosując splot sygnałów, a następnie ich porównywanie w dziedzinie częstotliwości (co wynika z jego równoważności z dyskretnym przekształceniem Fouriera), otrzymuje się dwa precyzyjne warunki do porównywania ich spójności: $\gamma_{x y}^{2}, \gamma_{x y}(\omega)$ i $A^{2}(\omega)\left(\gamma_{x y}(\omega)>0,7 ; A^{2}(\omega)<0,1\right)[5,6]$. 
Splot pozwala też badać kompleksowe relacje między dowolną liczbą sygnałów. I tak:

$$
\begin{gathered}
\left\{\mathrm{S}_{\mathrm{xx}}\right\}=\{\mathrm{x}\} *\{\mathrm{x}\} \\
\left\{\mathrm{S}_{\mathrm{xy}}\right\}=\{\mathrm{x}\} *\{\mathrm{y}\}=\{\mathrm{y}\} *\{\mathrm{x}\} \\
\left\{\mathrm{S}_{\mathrm{xyw}}\right\}=\{\mathrm{x}\} *\{\mathrm{y}\} *\{\mathrm{w}\} \\
\left\{\mathrm{S}_{\mathrm{xyw}}\right\}=[\{\mathrm{x}\} *\{\mathrm{y}\}] *\{\mathrm{w}\}=\{\mathrm{x}\} *[\{\mathrm{y}\} *\{\mathrm{w}\}]
\end{gathered}
$$

Ta własność jest szczególnie ważna, gdyż „otoczenie” i sygnały z badań diagnostycznych bardzo często są reprezentatywne przez kilka sygnałów (zbiorów pomiarów tych sygnałów). Można zatem dowolnie splatać splecione sygnały wejściowe ze splecionymi sygnałami wyjściowymi.

\section{Badanie statystycznych progów diagnostycznych koncentracji MOA Fe}

Bardzo ważnym elementem procesu diagnozowania jest wyznaczenie progów diagnostycznych. $[2,8,14] \mathrm{W}$ dotychczasowej praktyce diagnozowania progi wyznacza się na podstawie średniej pomiarów $A V(\mu)$ i odchylenia standardowego STD $(\sigma)$ dla wszystkich eksploatowanych silników (w rozpatrywanym przypadku są to silniki 1 i 2 - pomiary zmieszane rys. 1). Ustalono następujące progi diagnostyczne $[8,9,14,15]$ :

$-\mu+\sigma-$ dla zużycia normalnego;

$-\mu+2 \sigma-$ dla zużycia podwyższonego;

$-\mu+3 \sigma-$ dla zużycia wzmożonego;

$-\mu+$ ponad $3 \sigma-$ dla zużycia awaryjnego.

Następnie w celu zrealizowania wymaganego procesu diagnozowania wyznaczono indywidualne progi diagnostyczne dla silnika 1 i silnika 2 . Wyniki obliczeń progów dla $1 \div 12$ z 37 pomiarów) pomiarów indywidulanych dla silnika 1 i silnika 2 przedstawiono w tabelach 3 i 4 .

Tabela 3. MOA Fe - dla silnika 1

\begin{tabular}{|c|c|c|c|c|c|c|}
\hline $\begin{array}{l}\text { Liczba } \\
\text { pomiarów }\end{array}$ & $\begin{array}{c}\text { Prednia diag } \\
A V\end{array}$ & $\begin{array}{c}\text { Odchylenie } \\
\text { standardowe } S T D\end{array}$ & $A V+S T D$ & $A V+2 S T D$ & $A V+3 S T D$ & $R^{2}$ \\
\hline dla 3 pomiarów & 0,10 & 0,03 & 0,13 & 0,16 & 0,19 & 0,89 \\
\hline dla 4 pomiarów & 0,45 & 0,51 & 0,96 & 1,47 & 1,98 & 0,59 \\
\hline dla 5 pomiarów & 0,82 & 1,06 & 1,88 & 2,94 & 4,00 & 0,81 \\
\hline dla 6 pomiarów & 1,14 & 1,46 & 2,60 & 4,05 & 5,51 & 0,89 \\
\hline dla 7 pomiarów & 1,58 & 2,60 & 4,18 & 6,77 & 9,37 & 0,93 \\
\hline dla 8 pomiarów & 1,52 & 2,25 & 3,77 & 6,02 & 8,27 & 0,56 \\
\hline dla 9 pomiarów & 1,47 & 2,00 & 3,47 & 5,47 & 7,46 & 0,28 \\
\hline dla 10 pomiarów & 1,82 & 3,03 & 4,85 & 7,89 & 10,92 & 0,46 \\
\hline dla 11 pomiarów & 2,23 & 4,55 & 6,78 & 11,34 & 15,89 & 0,59 \\
\hline dla 12 pomiarów & 2,83 & 8,53 & 11,37 & 19,90 & 28,43 & 0,67 \\
\hline
\end{tabular}


Evaluation of diagnostic thresholds dependability for tribologic signals... Ocena wiarygodności progów diagnostycznych z sygnatów tribologicznych...

Tabela 4. MOA Fe - dla silnika 2

\begin{tabular}{|c|c|c|c|c|c|c|}
\hline $\begin{array}{l}\text { Próg diag. } \\
\text { Liczba } \\
\text { pomiarów }\end{array}$ & 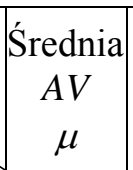 & $\begin{array}{c}\text { Odchylenie } \\
\text { standardowe } S T D \\
\sigma\end{array}$ & $\begin{array}{c}A V+S T D \\
\mu+\sigma\end{array}$ & $\begin{array}{r}A V+2 S T L \\
\mu+2 \sigma\end{array}$ & $\begin{array}{c}A V+2 S T D \\
\mu+3 \sigma\end{array}$ & $R^{2}$ \\
\hline dla 3 pomiarów & 0,43 & 0,20 & 0,64 & 0,84 & 1,04 & 0,36 \\
\hline dla 4 pomiarów & 0,43 & 0,14 & 0,56 & 0,70 & 0,83 & 0,24 \\
\hline dla 5 pomiarów & 0,62 & 0,30 & 0,92 & 1,22 & 1,52 & 0,17 \\
\hline dla 6 pomiarów & 0,77 & 0,37 & 1,13 & 1,50 & 1,87 & 0,43 \\
\hline dla 7 pomiarów & 0,86 & 0,36 & 1,23 & 1,59 & 1,95 & 0,52 \\
\hline dla 8 pomiarów & 1,04 & 0,56 & 1,60 & 2,16 & 2,72 & 0,66 \\
\hline dla 9 pomiarów & 1,57 & 3,01 & 4,58 & 7,59 & 10,60 & 0,63 \\
\hline dla 10 pomiarów & 1,52 & 2,70 & 4,22 & 6,92 & 9,62 & 0,41 \\
\hline dla 11 pomiarów & 1,54 & 2,44 & 3,98 & 6,42 & 8,86 & 0,34 \\
\hline dla 12 pomiarów & 1,66 & 2,37 & 4,03 & 6,41 & 8,78 & 0,38 \\
\hline
\end{tabular}

Analizując wyniki obróbki statystycznej pomiarów MOA Fe dla silnika 1 i 2 przedstawione w tabelach 3 i 4 stwierdza się, że obiekty te są zdecydowanie różne. Powinny być stąd traktowane indywidualnie. W procesie eksploatacji powstają trudności w interpretacji posiadanych wyników pomiarów. I tak np. w tabeli 1 dla 3. pomiaru mamy MOA $\mathrm{Fe}=0,3$, a wyliczony próg $\mu+3 \sigma$ przedstawiony $\mathrm{w}$ tabeli 3 wynosi 0,19 (źle), ale już dla 4. pomiaru w tabeli 1 mamy MOA $F e=1,5$, a wyliczony próg (tabela 3) wynosi 1,98 (dobrze). Tu należy zauważyć, że statystyki AV i SDT są estymatorami obciążonymi. Stąd wyniki mogą być niejednoznaczne (obarczone błędem).

Dodatkowe trudności interpretacyjne wynikają $\mathrm{z}$ tego, że 3. pomiar został zrealizowany po 1745 godz. nalotu i przy odpowiednio 12 i 5 wartości sygnału wibroakustycznego (tabela 1), a 4. pomiar po 1755 godz. nalotu i przy odpowiednio 9 i 7 wartości sygnału wibroakustycznego (tabela 1). Wiedza i intuicja ekspercka $\mathrm{w}$ takim trudnym przypadku analizy zbioru pomiarów sygnałów powinna być wspomagana specjalnymi badaniami relacji między wszystkimi sygnałami. Statystyki AV i SDT staną się parametrami $\mu$ i $\sigma$ (zatem estymatorami nieobciążonymi) gdy zbiory pomiarów będą „spójne”.

Dlatego badanie spójności zbiorów pomiarów, z których wyliczany jest próg diagnostyczny w powiązaniu z otoczeniem jest potrzebne (nawet konieczne). 


\section{Badanie spójności zbiorów pomiarów na podstawie współczynnika koherencji}

Bazując na wzorze (17) można zapisać wzór na koherencję 3 sygnałów x, y i w.

$$
\gamma_{x w y}^{(3)}(\omega)=\frac{\left|S_{x y w}\right|^{3}}{s_{x x x} S_{y y y} S_{w w w}}
$$

gdzie:

$S_{x y w}$ - splot wzajemny (iloczyn Cauchy'ego) sygnału otoczenia $x$ (nalotu), sygnału otoczenia $w$ (wibroakustycznego) i sygnału diagnostycznego $y$ (koncentracji MOAFe);

$S_{x x x}-$ splot własny sygnału $x$;

$S_{w w w}$ - splot własny sygnału $w$;

$S_{y y y}-$ splot własny sygnału $y$.

Zestawienie obliczeń dla silnika 1 (rys. 2, tabela 1)

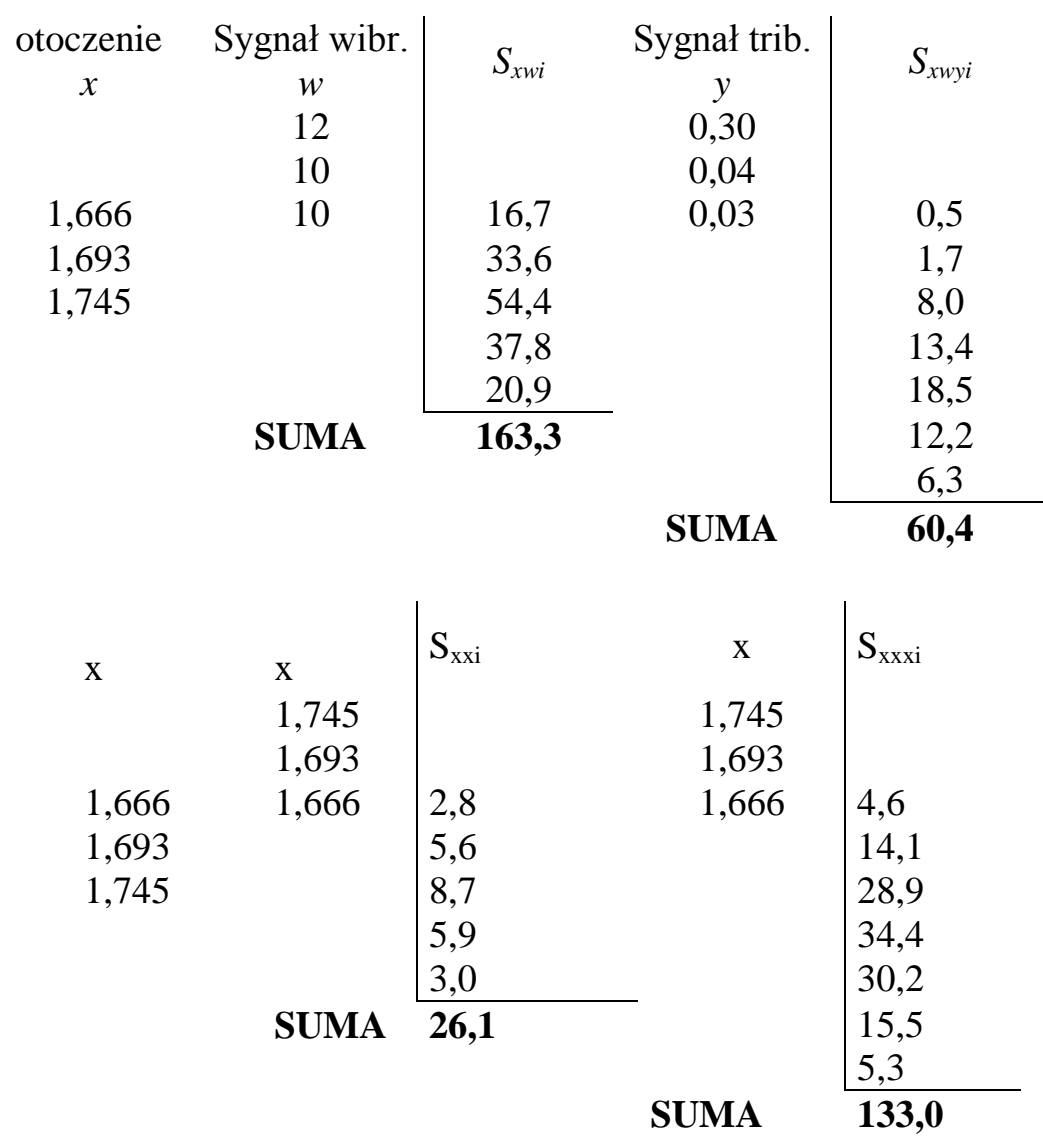


Evaluation of diagnostic thresholds dependability for tribologic signals...

Ocena wiarygodności progów diagnostycznych z sygnałów tribologicznych...

\begin{tabular}{|c|c|c|c|c|}
\hline \multirow[t]{2}{*}{$\mathrm{w}$} & W & $S_{w w i}$ & W & $\mathrm{S}_{\mathrm{wwwi}}$ \\
\hline & 12 & & 12 & \\
\hline \multirow{8}{*}{$\begin{array}{l}10,00 \\
10,00 \\
12,00\end{array}$} & 10 & 100 & 10 & 1000 \\
\hline & & 200 & & 3000 \\
\hline & & 340 & & 6600 \\
\hline & & 240 & & 8200 \\
\hline & & 144 & & 7920 \\
\hline & SUMA & 1024 & & 4320 \\
\hline & & & & 1728 \\
\hline & & & & 32768 \\
\hline
\end{tabular}

\begin{tabular}{ll|ll|l}
$\mathrm{y}$ & $\mathrm{y}$ & $\mathrm{S}_{\mathrm{yyi}}$ & $\mathrm{y}$ & $\mathrm{S}_{\mathrm{yyyi}}$ \\
& 0,30 & & 0,30 & \\
0,03 & 0,04 & & 0,04 & \\
0,04 & 0,03 & 0,001 & 0,03 & 0,00003 \\
0,30 & & 0,002 & & 0,00011 \\
& & 0,020 & & 0,00095 \\
& & 0,024 & & 0,00222 \\
& & 0,090 & & 0,00954 \\
& SUMA & $\mathbf{0 , 1 3 7}$ & & 0,01080 \\
& & & & \\
& & & & $\mathbf{0 , 0 5 0 6 5}$
\end{tabular}

\begin{tabular}{crrrrc}
\multicolumn{1}{l}{$S_{x w y i}$} & \multicolumn{1}{c}{$S_{x x x i}$} & \multicolumn{1}{c}{$S_{w w w i}$} & \multicolumn{1}{l}{$S_{y y y i}$} & $\gamma_{x w y}^{(3)}(\omega)$ & $A^{2}=\frac{S_{y y y}}{S_{x x x} S_{w w w}}$ \\
0,5 & 4,6 & 1000 & 0,00003 & 0,00002 & $5,84 \mathrm{E}-18$ \\
1,7 & 14,1 & 3000 & 0,00011 & 0,00062 & $2,55 \mathrm{E}-18$ \\
8,0 & 28,9 & 6600 & 0,00095 & 0,06657 & $5,01 \mathrm{E}-18$ \\
13,4 & 34,4 & 8200 & 0,00222 & 0,31500 & $7,89 \mathrm{E}-18$ \\
18,5 & 30,2 & 7920 & 0,00954 & 0,82507 & $3,99 \mathrm{E}-17$ \\
12,2 & 15,5 & 4320 & 0,01080 & 0,23663 & $1,62 \mathrm{E}-16$ \\
6,3 & 5,3 & 1728 & 0,02700 & 0,03257 & $2,94 \mathrm{E}-15$
\end{tabular}


Paweł Lindstedt, Marek Zboiński, Maciej Deliś, Jerzy Manerowski

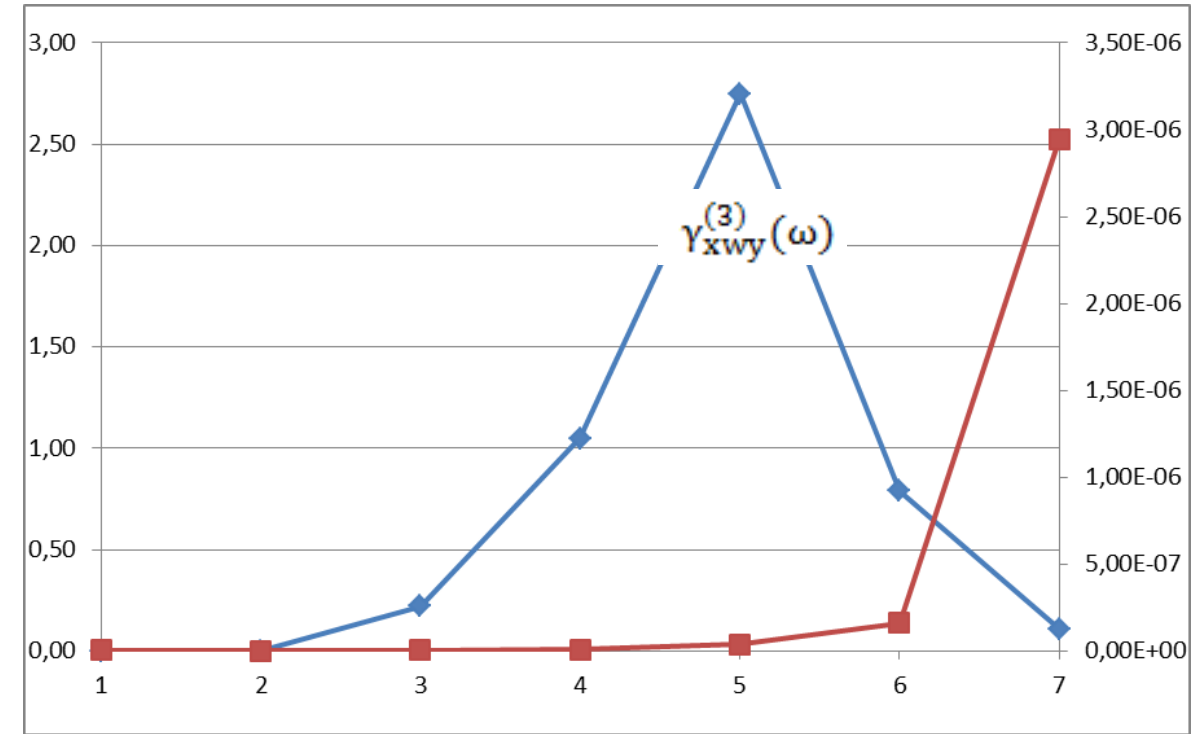

Rys. 3 Przebiegi $\gamma_{x w y}^{(3)}(\omega)=\frac{\left|S_{x w y}\right|^{3}}{S_{x x x_{\max }} S_{y y y_{\max }} S_{w w w \max }} i A^{2}$

dla 3 pomiarów (silnik 1)

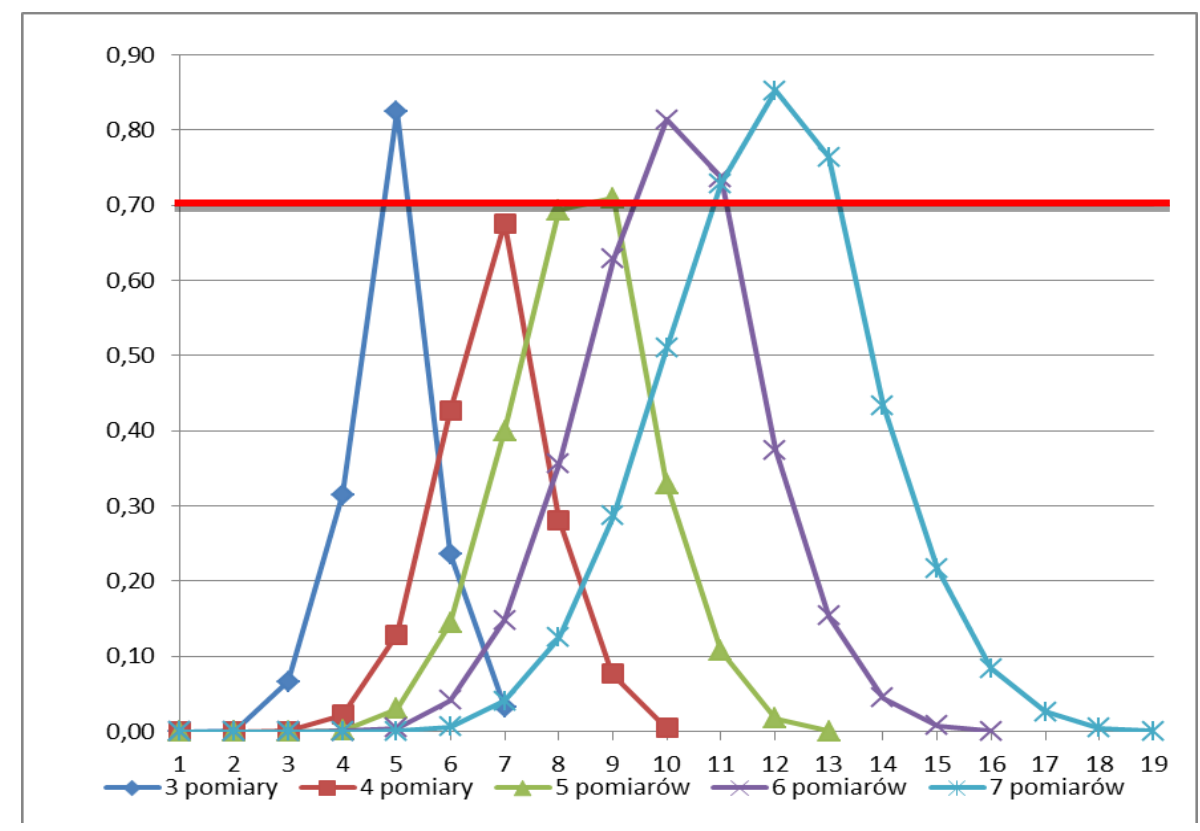

Rys. 4 Zestawienie przebiegów $\gamma_{x w y}^{(3)}(\omega)$ dla $3 \div 7$ pomiarów dla silnika 1 (przekroczenie warunku $\gamma_{x w y}^{(3)}(\omega)=0,7$ świadczy o dostatecznej spójności części zbiorów pomiarów) 
Evaluation of diagnostic thresholds dependability for tribologic signals...

Ocena wiarygodności progów diagnostycznych z sygnałów tribologicznych...

Zestawienia obliczeń dla silnika 2 (rys 2, tabela 2)

\begin{tabular}{cc|cc|c} 
otoczenie & $\begin{array}{c}\text { Sygnal } \\
\text { wibr. }\end{array}$ & $S_{x w i}$ & $\begin{array}{c}\text { Sygnal } \\
\text { trib. }\end{array}$ & $S_{x w y i}$ \\
& $w$ & & $y$ & \\
& 32 & & 0,0 & \\
& 14 & & 0,9 & \\
1,666 & 22 & 36,7 & 0,4 & 14,7 \\
1,693 & & 60,6 & & 57,2 \\
1,745 & & 115,4 & & 101,0 \\
& & 78,6 & & 135,9 \\
& & 55,8 & & 94,2 \\
& \multirow{2}{*}{ SUMA } & 347,1 & & 51,0 \\
& & & & 0,6 \\
& & & & SUMA
\end{tabular}

\begin{tabular}{|c|c|c|c|c|}
\hline \multirow[t]{3}{*}{$\mathrm{X}$} & $\mathrm{X}$ & $S_{x x i}$ & $\mathrm{X}$ & $S_{x x x i}$ \\
\hline & 1,745 & & 1,745 & \\
\hline & 1,693 & & 1,693 & \\
\hline \multirow{2}{*}{$\begin{array}{l}1,666 \\
1,693\end{array}$} & 1,666 & 2,8 & 1,666 & 4,6 \\
\hline & & 5,6 & & 14,1 \\
\hline \multirow[t]{6}{*}{1,745} & & 8,7 & & 28,9 \\
\hline & & 5,9 & & 34,4 \\
\hline & & 3,0 & & 30,2 \\
\hline & SUMA & 26,1 & & 15,5 \\
\hline & & & & 5,3 \\
\hline & & & SUMA & $\overline{133,0}$ \\
\hline
\end{tabular}

\begin{tabular}{|c|c|c|c|c|}
\hline \multirow{3}{*}{ W } & $\mathrm{W}$ & \multirow[t]{3}{*}{$\mathrm{S}_{\mathrm{wwi}}$} & w & \multirow{3}{*}{$S_{\text {wwwi }}$} \\
\hline & 32 & & 32 & \\
\hline & 14 & & 14 & \\
\hline 22 & \multirow[t]{5}{*}{22} & 484 & \multirow[t]{7}{*}{22} & 10648 \\
\hline 14 & & 616 & & 20328 \\
\hline 32 & & 1604 & & 59400 \\
\hline & & 896 & & 61880 \\
\hline & & 1024 & & 86400 \\
\hline & \multirow[t]{3}{*}{ SUMA } & 4624 & & 43008 \\
\hline & & & & 32768 \\
\hline & & & \multicolumn{2}{|c|}{ SUMA } \\
\hline
\end{tabular}


Paweł Lindstedt, Marek Zboiński, Maciej Deliś, Jerzy Manerowski

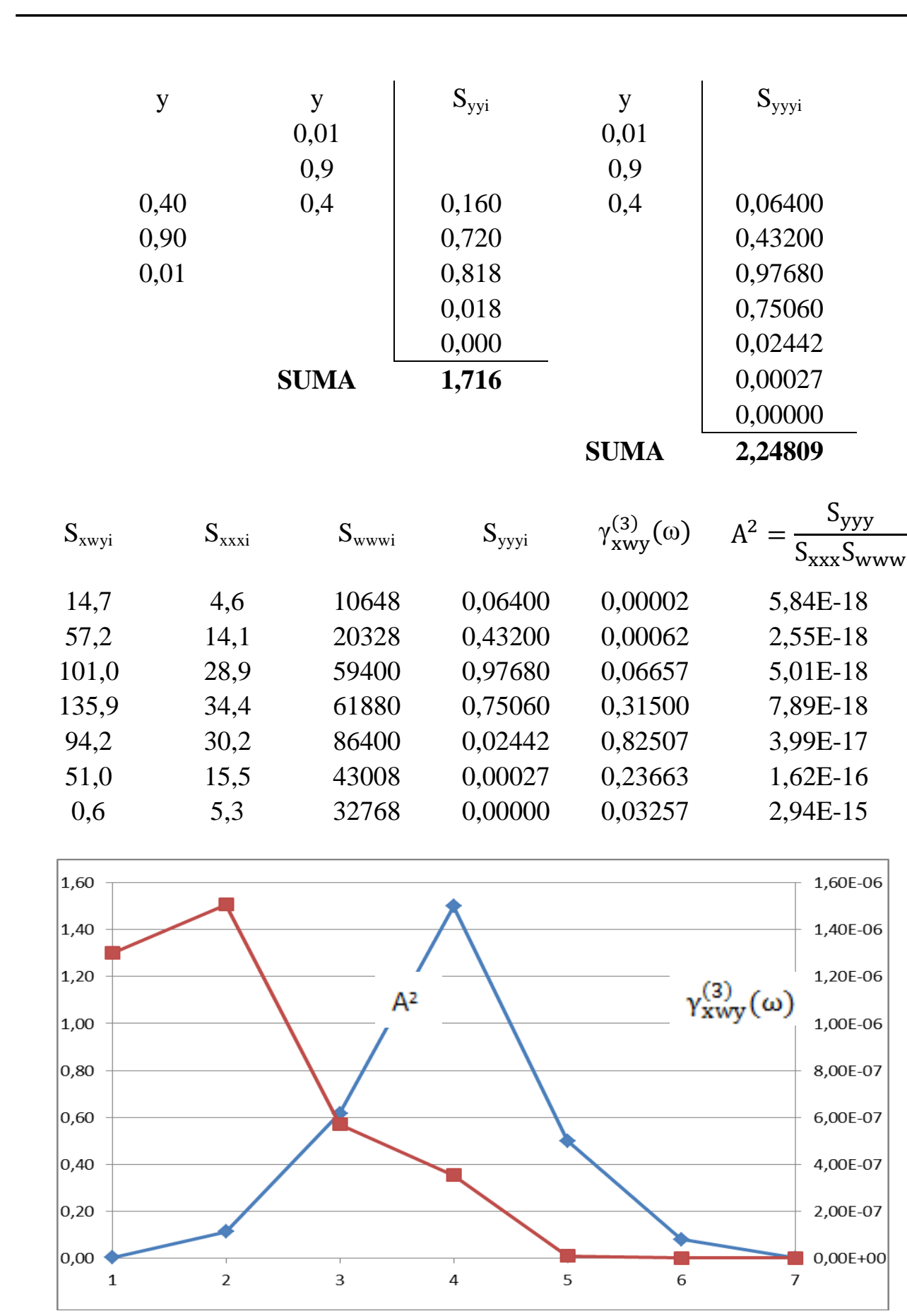

Rys. 5 Przebiegi $\gamma_{x w y}^{(3)}(\omega)=\frac{\left|S_{x w y}\right|^{3}}{S_{x x x_{\max }} S_{y y y_{\max }} S_{w w w \max }} i A^{2}$ dla 3 pomiarów (silnik 2) 
Evaluation of diagnostic thresholds dependability for tribologic signals... Ocena wiarygodności progów diagnostycznych z sygnatów tribologicznych...

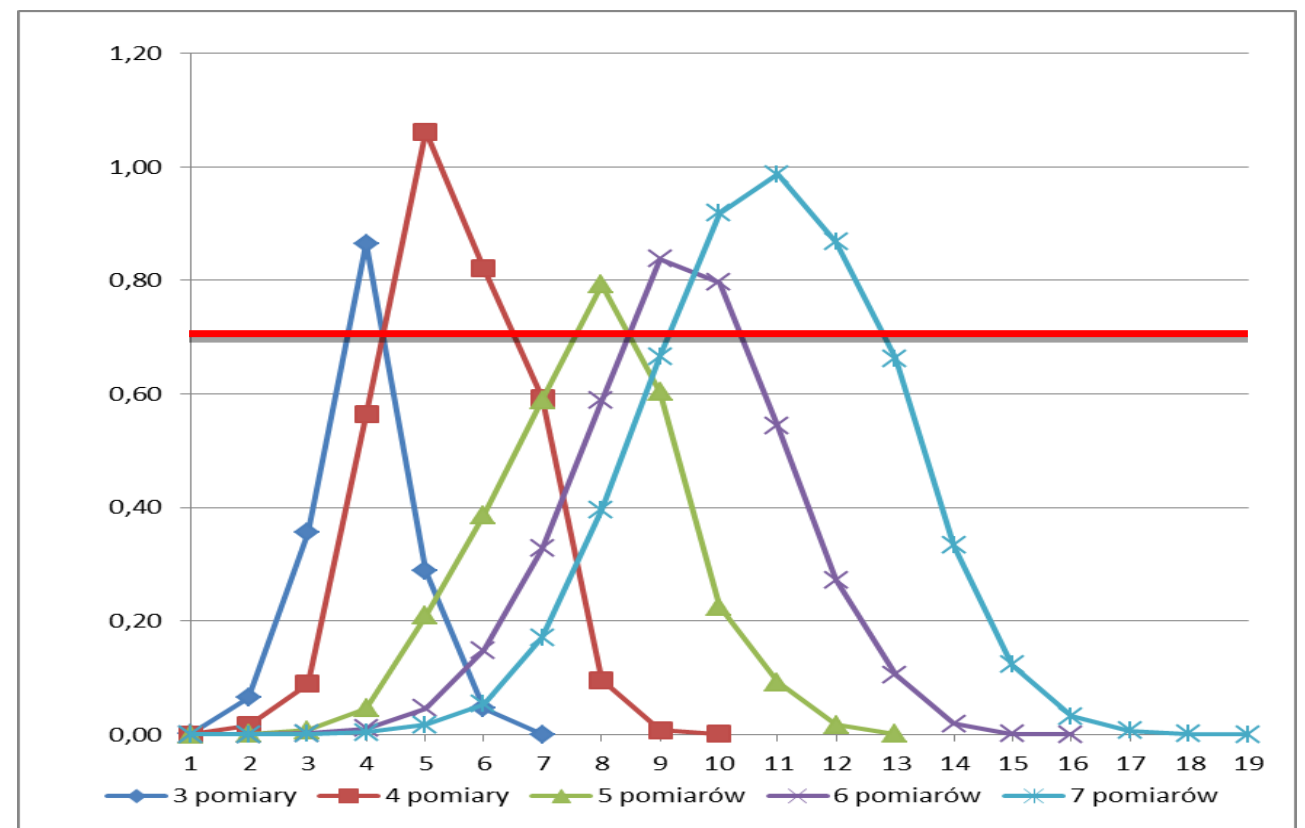

Rys. 6 Zestawienie przebiegów $\gamma_{x w y}^{(3)}(\omega)$ dla $3 \div 7$ pomiarów dla silnika 2 (przekroczenie warunku $\gamma_{x w y}^{(3)}(\omega)=0,7$ świadczy o dostatecznej spójności wszystkich zbiorów pomiarów)

Z porównania przebiegów współczynników koherencji liniowej obliczonej z iloczynu Cauchy'ego widać, że zbiory pomiarów MOA Fe (analizowane wg warunku spójności $\left.\gamma_{\mathrm{xwy}}^{(3)}(\omega)>0,7\right)$ dla silnika 1 są mniej spójne od pomiarów zbiorów pomiarów silnika 2. Stąd wniosek, że progi diagnostyczne wyznaczone dla silnika 2 są bardziej wiarygodne. Jest to też zgodne z intuicją eksperta. W procesie diagnozowania obiektów technicznych szczególna rolę odgrywa ekspert. Jego zadaniem jest ustalenie wagi zmian jakie występują w zbiorach pomiarów (stosuje się tu typowe sposoby kodowania danych) [10].

\section{Podsumowanie}

Wyznaczenie progu diagnostycznego jest podstawowym warunkiem dokładności i wiarygodności diagnozowania. Bez prawidłowo wyznaczonego progu diagnostycznego nie można prawidłowo przeprowadzić procesu diagnozowania. Wyznaczenie progu diagnostycznego jest niestety trudne szczególnie wtedy, gdy dysponuje się małym zbiorem pomiarów (3, 4 itp.), a problem ten zawsze występuje, gdy rozpoczynamy proces użytkowania diagnozowanych obiektów. Środkiem pomocniczym w ustaleniu wiarygodności wyznaczonego (z małej liczby 
pomiarów) progu diagnostycznego mogą być wskaźniki spójności zbiorów pomiarów sygnałów bazujących na kowariancji (korelacji) lub koherencji (splocie) dyskretnych sygnałów.

Gdy współczynniki kowariancji lub koherencji są większe od 0,7 to należy uznać, że zbiory pomiarów są dostatecznie spójne $[1,3,6,11,12]$, a wyznaczone na ich podstawie progi diagnostyczne wiarygodne, a stąd wypracowana diagnoza prawidłowa.

\section{Literatura}

[1] Bendat J. S., Piersol A. G.: Metody analizy i pomiaru sygnałów losowych, PWN, Warszawa 1968.

[2] Borowczyk H.: Model kompleksowego systemu diagnostycznego płatowca i zespołu napędowego statku powietrznego, V Międzynarodowa Konferencja AIRDIAG'97, Wyd. ITWL, Warszawa 1997.

[3] Bracewell R.: Przekształcenie Fouriera i jego zastosowania, WNT, Warszawa 1968.

[4] Deliś M., Diagnosis of aircraft engines tribological systems with the ferrography method, Journal of KONBiN, 2011, Nr 1, s. 67-74.

[5] Franks L.E., Teoria sygnałów, WNT, Warszawa 1975.

[6] de Larminat P., Thomas Y.: Automatyka: układy liniowe; Sygnały i układy. Warszawa : Wydaw. Nauk.-Techn., 1983.

[7] Lindstedt P.: Statistical Diagnostic Thresholds of Rolling Bearings with Correlation of the Bearings Signal and its Environment Based on Cauchy Product; Solid State Phenomena, 2013, Trans-Tech Publications, DurntenZurich, pp. 111-116.

[8] Lindstedt, P., Sudakowski, T., The Method of Assessment of Suitability of the Bearing System Based on Parameters of Technical and Adjustment State, Solid State Phenomena, 2013, Trans-Tech Publications, Durnten-Zurich, pp. 73-78.

[9] Lindstedt P., Zboiński M., Deliś M., Spychała J., Kowalski M.: Korelacyjnowidmowa metoda diagnozowania układów łożyskowania $\mathrm{z}$ wykorzystaniem sygnałów zużyciowych w procesie eksploatacji napędów turbinowych. Prace naukowe ITWL, No 34 Warszawa, 2014.

[10] Łomnicki A.: Wprowadzenie do statystyki, PWN, Warszawa 2003.

[11] Osiowski J.: Zarys rachunku operatorowego, WNT, Warszawa 1981.

[12] Sołodnikow W.W., Dynamika statyczna liniowanych układów sterownia automatycznego, WNT, Warszawa 1964. 
Evaluation of diagnostic thresholds dependability for tribologic signals...

Ocena wiarygodności progów diagnostycznych z sygnatów tribologicznych...

[13] Szabatin J.: Podstawy teorii sygnałów, WKŁ, Warszawa 2000 .

[14] Zboiński M., Lindstedt P., Kotlarz I.: Stałe i aktualizowane statystyczne tribologiczne progi diagnostyczne i ich znaczenie w procesie bieżącej oceny stanu technicznego układu łożyskowania silnika lotniczego, Journal of KONBIN 1(17) 2011, Warszawa 2011.

[15] Zboiński, M., Lindstedt, P., Deliś, M., Opportunities of evaluation diagnostic test results of roller bearings from signals correlation of bearing and its environment, Journal of KONBIN Vol. 2 (22), pp. 109-118, Warszawa 2012.

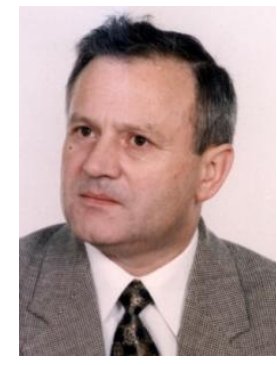

prof. Jerzy Manerowski - Profesor zwyczajny, Politechnika Warszawska, Wydziat Transportu; Instytut Techniczny Wojsk Lotniczych; dyscyplina - mechanika, budowa i eksploatacja maszyn, transport; czlonek Centralnej Komisji ds. Stopni i Tytułów; członek Wydziału IV Nauk Technicznych - Komitet Transportu Polskiej Akademii Nauk. Obszary badawcze: identyfikacja $i$ modelowanie dynamiki lotów statków powietrznych $z$ wykorzystaniem sztucznych sieci neuronowych.

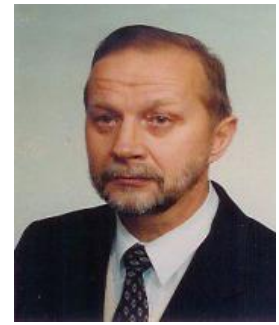

prof. dr hab. inz. Pawet Lindstedt - profesor Politechniki Białostockiej, profesor zwyczajny Instytutu Technicznego Wojsk Lotniczych. Tematyka badawcza: budowa i eksploatacja maszyn, automatyka stosowana, diagnostyka i niezawodność maszyn. Prace dotycza diagnozowania silników lotniczych, ukladów tożyskowania metodami funkcjonalnymi, wibroakustycznymi i zużyciowymi.

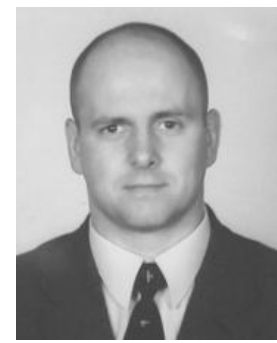

dr inż. Marek Zboiński - adiunkt, kierownik Akredytowanego Laboratorium Diagnostyki Systemów Tribologicznych w Instytucie Technicznym Wojsk Lotniczych. Prace dotycza diagnozowania silników lotniczych, układów tożyskowania metodami zużyciowymi.

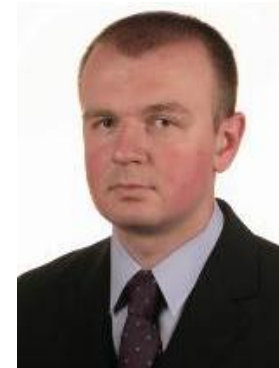

dr inż. Maciej Deliś - starszy inżynier w Pracowni Diagnostyki Systemów Tribologicznych Zakladu Silników Lotniczych Instytutu Technicznego Wojsk Lotniczych. 